\title{
POLISSACARÍDEOS EXTRAÍDOS DE ALGAS MARINHAS E SUAS APLICAÇÕES BIOTECNOLÓGICAS: UMA REVISÃO
}

\author{
Andreanne Gomes Vasconcelos \\ Graduada em Bacharelado em Biomedicina e Mestranda em Biotecnologia pela \\ Universidade Federal do Piauí (UFPI). Membro do Núcleo de Pesquisa em Biodiversidade \\ e Biotecnologia (BIOTEC). andreannegv@gmail.com \\ Karla Vasconcelos de Araújo \\ Aluna de graduação em Licenciatura em Ciências Biológicas pela Universidade Federal do \\ Piauí (UFPI). karla-vasconcelos-@ hotmail.com \\ Lucas de Araújo Bastos Santana \\ Graduado em Bacharelado em Biomedicina e Mestrando em Biotecnologia pela \\ Universidade Federal do Piauí (UFPI). lucassantanasrn@ hotmail.com
}

\begin{abstract}
RESUMO
A biodiversidade marinha brasileira tem sido reconhecida por ser fonte de compostos com propriedades biológicas diversas. As algas marinhas são consideradas fontes valiosas de diversos compostos bioativos, entre eles os polissacarídeos. Os principais polissacarídeos conhecidos de algas marinhas são carragenanas, agaranas e alginatos, mas também são relatadas as galactanas híbridas, fucanas e laminarinas. Algumas dessas macromoléculas apresentam alguns dos grupos hidroxila dos resíduos de açúcar substituídos por grupamentos sulfato, sendo chamados de polissacarídeos sulfatados. Em linhas gerais, os polissacarídeos extraídos de algas marinhas apresentam várias atividades biológicas com potenciais benefícios para a saúde, tais como atividade anticoagulante e antitrombótica, antiviral, anti-tumor, imunomodulatória, antioxidante e anti-hiperlipêmica, e aplicações bastante diversificadas na área de alimentos, farmacêutica, biomédica e biotecnológica. No Brasil, a exploração de espécies com fins comerciais de maior porte corresponde à coleta de algas vermelhas no litoral do nordeste. Entretanto, as algas marinhas ainda são um recurso pouco explorado no Brasil, sendo necessário potencializar os recursos científicos, tecnológicos e financeiros, bem como diminuir a distância entre pesquisas em polissacarídeos de algas e produção e exploração no mercado.
\end{abstract}

PALAVRAS-CHAVE: Carragenana, agarana, alginato, polissacarídeos sulfatados.

\section{POLYSACCHARIDES EXTRACTED FROM SEAWEED AND THEIR APPLICATIONS BIOTECHNOLOGICAL: A REVIEW}

\section{SUMMARY}

Brazilian marine biodiversity has been recognized as a source of compounds with biological properties. Seaweeds are considered valuable sources of many bioactive compounds, including polysaccharides. The main polysaccharides from marine algae are carrageenans, alginates and agarans, but are also reported hybrid galactans, fucans and laminarins. Some of these macromolecules exhibit some of the hydroxyl groups of the sugar residues replaced by sulfate groups, being called sulfated polysaccharides. In general, the polysaccharides extracted from seaweed have several biological activities with potential health benefits, such as anticoagulant and antithrombotic, antiviral, anti-tumor, 
immunomodulatory, antioxidant and anti-hyperlipemic activity, and diverse applications in the field of food, pharmaceutical, biomedical and biotechnology. In Brazil, the exploitation of commercial species corresponds to the collection of red algae in the coastal region. However, the seaweeds are still a feature explored in Brazil, being necessary to enhance the scientific, technological and financial resources, as well as bridge the gap between research and production of algae polysaccharides and market exploitation.

KEYWORDS: Carrageenan, agarans, alginate, sulfated polysaccharides

\section{POLISSACARÍDEOS EXTRAÍDOS DE ALGAS MARINHAS E SUAS APLICAÇÕES BIOTECNOLÓGICAS: UMA REVISÃO}

\section{INTRODUÇÃO}

Os polissacarídeos são polímeros de carboidratos que podem ser formados de um tipo único de monossacarídeos ou de diferentes tipos. Essas macromoléculas são solúveis em água, onde desempenham importante papel como espessante, gelificante, emulsificante e hidratante (RINAUDO, 2008). Os polímeros naturais de modo geral são inertes, seguros, não-tóxicos, biocompativeis, biodegradáveis, de baixo custo, não causam danos ao meio ambiente e são encontrados em abundância na natureza (GUO et al., 1998; PRAJAPATI et al., 2014). Essas características conferem excelentes condições de aplicabilidade variada na indústria, principalmente de alimentos e farmacêutica.

Os polissacarídeos são ricos em grupos $\mathrm{OH}$ capazes de formar interações de pontes de hidrogênio intra ou intermoleculares, o que controla a solubilidade dos polímeros (RINAUDO, 2004). São capazes de formar conformações helicoidais em solução devido à sua estereoregularidade; sua conformação ordenada tem uma caráter semi-rígido e a sua estabilidade depende não só do $\mathrm{pH}$ e da força iónica do meio, mas também da temperatura e da concentração de determinadas moléculas e se a estrutura do polissacárido contém unidades de ácido urônico ou substituintes iônicos (RINAUDO, 2006, 2008; PRAJAPATI et al., 2014).

Os polissacarídeos são comumente encontrados em fontes animais, fungos, bactérias e plantas - incluindo as algas (RINAUDO, 2008; CUNHA, DE PAULA e FEITOSA, 2009). A biodiversidade marinha brasileira tem sido reconhecida por ser fonte de compostos com propriedades biológicas diversas. A extensa costa entre as zonas das marés, de cerca de $8.500 \mathrm{Km}$, é dominada pelas algas, entre macro e microalgas, cada uma das quais sendo consideradas fontes valiosas de diversos compostos bioativos, tais como polifenois, carotenoides, pigmentos, enzimas e polissacarídeos (GIULIETTI et al., 2005; PEREIRA et al., 2014).

Dentre esses compostos, os polissacarídeos de algas vêm se destacando devido às suas atividades biológicas e sua abundância nos organismos marinhos. Os principais polissacarídeos conhecidos de algas marinhas são carragenanas, agaranas e alginatos, mas também são relatadas as galactanas híbridas, fucanas e laminarinas (PRAJAPATI et al., 2014, RINAUDO, 2008; HAROUN-BOUHEDJA et al., 2000; ROCHA et al., 2004; DEVILLÉ et al., 2007). 
Em linhas gerais, os polissacarídeos extraídos de algas marinhas apresentam várias atividades biológicas com potenciais benefícios para a saúde, e aplicações bastante diversificadas na área de alimentos, farmacêutica, biomédica e biotecnológica.

\section{CARACTERÍSTICAS DAS ALGAS MARINHAS}

As algas marinhas são organismos semelhantes às plantas e habitam diferentes ambientes, desde que disponham de luz e umidade suficientes (VIDOTTI e ROLLEMBERG, 2004). As algas comumente pertencem a quatro grupos diferentes determinados com base na cor, sendo elas: algas azuis; algas vermelhas; algas verdes e algas pardas (KILINÇ et al., 2013). As algas vermelhas (filo Rhodophyta), com cerca de 6000 espécies, são quase que unicamente pluricelulares e marinhas (típicas em mares quentes), vivem fixadas em um substrato e sua principal característica é a presença do pigmento que confere a coloração característica destes organismos, a ficoeritrina (KILINÇ et al., 2013; VIDOTTI e ROLLEMBERG, 2004).

As algas marrons ou algas pardas (filo Ochrophyta, classes: Phaeophyceae), com cerca de 1.750 espécies, são organismos pluricelulares predominantemente marinhos (típicos em mares frios), vivendo fixados em um substrato ou flutuando, formando imensas florestas submersas (KILINÇ et al., 2013).

As algas verdes (filo Chlorophyta, classes: Bryopsidophyceae, Chlorophyceae, Dasycladophyceae, Prasinophyceae e Ulvophyceae), com cerca de 1200 espécies, são extremamente abundantes nos ambientes aquáticos, habitando águas doces ou salgadas, solos úmidos ou troncos, e contêm os pigmentos clorofilas a e b, carotenos e xantofilas (KILINÇ et al., 2013; VIDOTTI e ROLLEMBERG, 2004).

Nas algas vermelhas, encontram-se as galactanas sulfatadas, que atualmente tem despertado o interesse de vários pesquisadores; das algas marrons extraem-se as fucanas (homofucanas) e os fucoidanos (heterofucanas); as algas verdes apresentam polissacarídeos sulfatados mais heterogêneos que são ricos em galactose, manose, xilose, arabinose, glicose e ou ácidos urônicos (ROCHA et al., 2004). Os grupos de algas de importância para a extração de polissacarídeos são mostrados na figura 1.
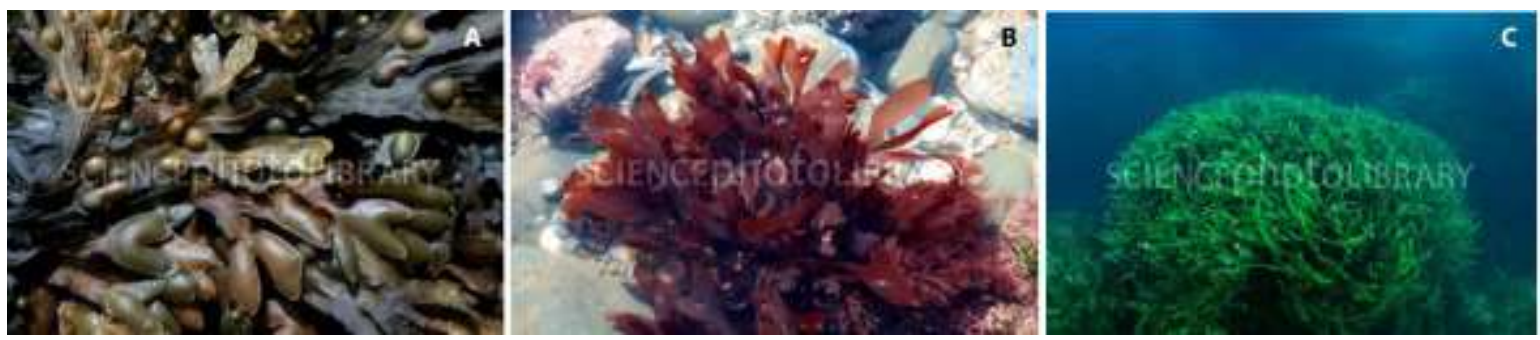

Figura 1. Grupos de algas de importância para a extração de polissacarídeos. A) Alga marron, B) Alga vermelha, C) Alga verde. Fonte: Science Photo Library.

As macroalgas marinhas tem uma importância tanto comercial quanto ecológica. Elas são cruciais por estarem na base das cadeias alimentares aquáticas e serem responsáveis por uma grande produção de oxigênio (KILINÇ et al., 2013). Alga é um produto muito versátil, amplamente utilizada como fertilizantes e adubos na agricultura, na alimentação humana e animal, em uso medicinal e na exploração de ficocolóides e compostos bioativos 
(VERKLEIJ, 1992; MABEAL e FLEURENCE, 1993; GLICKSMAN, 1987; HOLDT e KRAAN, 2011).

\section{PRINCIPAIS POLISSACARÍDEOS EXTRAÍDOS DE ALGAS MARINHAS}

\section{Carragenanas}

A carragenana foi assim chamada porque foi primeiramente usada por habitantes de uma cidade chamada Carragena, na Irlanda, onde os extratos de algas vermelhas já eram usados para alimentos e medicamentos há alguns séculos (PRAJAPATI et al., 2014). Trata-se de um polissacarídeo sulfatado, de cadeia linear, aniônico, extraído de certas algas vermelhas da Família Rhodophyceae (PEREIRA, 2013). A carragenana tem propriedades gelificante, estabilizante e espessante, além de características como biocompatibilidade, biodegradabilidade, elevada capacidade de retenção de água e a resistência mecânica dos seus géis (PRAJAPATI et al., 2014).

Sua presença já foi relatada em Chondrus cripus (WONG e CRAIGIE, 1978) e Gigartina stellata (MATHIESO e TVETER, 1976), que são espécies de macroalgas comuns no Atlântico Norte. Também foram relatadas em algas do gênero Eucheuma (SANTOS, 1989), Sarconema sp. (KUMAR, GODIYA e SIDDHANTA, 2012; CHIOVITTI et al., 1998), Iridaea (MCCANDLESS, CRAIGIE e HANSEN, 1975; MATULEWICZ e CEREZO, 1980) e nas espécies Hypnea musciformis (GREER et al., 1984; KNUTSEN et al., 1995), Solieria chordalis (BONDU et al., 2010), Kappaphycus alvarezii (WEBBER, CARVALHO e BARRETO, 2012). Dentre essas, Chondrus crispus, Gigartina stellata, Iridaea spp., Euchema spp. e Kappaphycus spp. são as algas mais popularmente usadas para a extração de carragenana com fins comerciais (PRAJAPATI et al., 2014; ROSA, 1972).

As carragenanas são compostas de unidades alternadas de galactose modificada, cuja estrutura é uma cadeia linear de resíduos $\beta$-D-galactose ligados através das posições 1 e 3 (unidade A) a resíduos $\alpha$-D-galactose ligadas através das posições 1 e 4 (unidade B) arranjadas em unidades dispostas numa sequência alternada (AB)n (RINAUDO, 2008; CUNHA, DE PAULA e FEITOSA, 2009). A unidade A pode transportar grupos de metiléter na posição 6 , grupos sulfatos hemi-éster nas posições 2,4 ou 6; e algumas unidades $A$ podem transportar ácido pirúvico. A unidade B pode transportar grupos metil na posição 2 ou grupo 4-O-metil- $\alpha$-L-galactopiranosil na posição 6 e/ou grupos sulfatos hemi-éster na posição 2 ou 6 , ou em ambas. A unidade B ( $\alpha$-D-galactose) pode ser total ou parcialmente convertido em formas de 3,6-anidro por eliminação de sulfato a partir da posição 6 (RINAUDO, 2008).

Dependendo da quantidade e da posição dos grupos $\mathrm{SO}_{3}$, as carragenanas são classificadas em $\lambda$ (lambda), $\kappa$ (kappa), 1 (iota), $v$ (nu), $\mu$ (mu), $\theta$ (teta) e $\xi$ (Ksi) (figura 2), todas contendo cerca de 22-35\% de grupos sulfato (PRAJAPATI et al., 2014). As $\kappa$ - e $\lambda$ carragenanas representam, respectivamente, cerca de 40 e $60 \%$ do extrato não fracionado de algas vermelhas (ROSA, 1972) e constituem o foco comercial. Carragenanas disponíveis comercialmente são extraídas de Eucheuma cottonii na forma k-carragenana e de Eucheuma spp. na forma iota (Marcel Trading Corporation). 


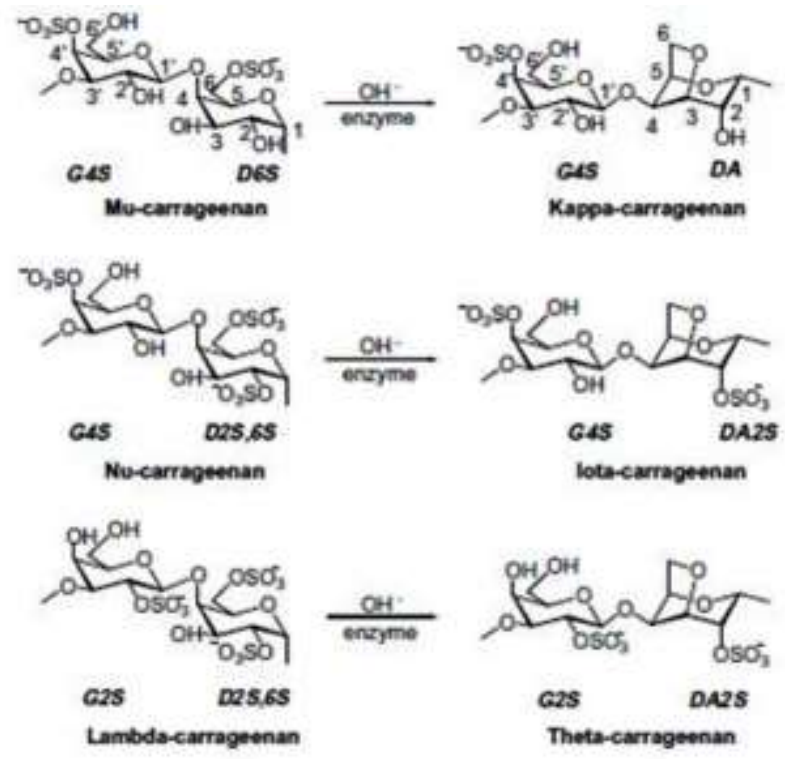

Figura 2. Representação das diferentes estruturas das unidades dimérica de carragenanas comerciais e estruturas relacionadas. $\beta$-D-galactose ligados na posição 3 (unidade G) e $\alpha$-D-galactose ligadas ligados na posição 4 (unidade D) ou 3,6-anidro- $\alpha$ -

D-galactose (unidade DA). Fonte: CAMPO et al., 2009.

As carragenanas comerciais tem se consolidado no mercado por empresas como Marcel Trading Corporation e FMC Health and Nutrition, em formulações de alimentos, de medicamentos e cosméticos. As principais marcas de carragenana relatada disponível no mercado são: Gelcarin ${ }^{\circledR G P-812 N F}$ e Gelcarin ${ }^{\circledR G P-911 N F}$ ( $\kappa$-carragenana), Gelcarin ${ }^{\circledR}$ GP$379 \mathrm{NF}$ e SeaSpen ${ }^{\circledR P F}$ (1-carragenana), Viscarin ${ }^{\circledR}$ GP-109NF e Viscarin ${ }^{\circledR G P}-209 N F(\lambda$ carragenana). Há um número considerável de patentes em carragenanas que podem ser vistas na tabela 1.

Tabela 1. Algumas patentes em polissacarídeos de algas.

\begin{tabular}{|c|c|c|c|c|}
\hline $\begin{array}{c}\text { POLISSAC } \\
\text { ARÍDEO }\end{array}$ & $\begin{array}{c}\mathrm{N}^{\circ} \mathrm{DA} \\
\text { PATENTE }\end{array}$ & TÍTULO & $\begin{array}{c}\text { DATA DE } \\
\text { PUBLICAÇÃO }\end{array}$ & AUTORES \\
\hline \multirow[t]{6}{*}{ Carragenana } & $\begin{array}{c}\text { US } \\
3280102\end{array}$ & $\begin{array}{l}\text { Preparation of carrageenan } \\
\text { having improved water } \\
\text { dispersibility }\end{array}$ & 18 out. 1966 & $\begin{array}{l}\text { Gordon, A.L., } \\
\text { Jones, J.J., e } \\
\text { Pike, L.F. }\end{array}$ \\
\hline & $\begin{array}{c}\text { US } \\
3907770\end{array}$ & $\begin{array}{l}\text { Process of extracting } \\
\text { carrageenan from seaweed }\end{array}$ & 23 set. 1975 & $\begin{array}{l}\text { Strong, C. H. } \\
\text { G. }\end{array}$ \\
\hline & $\begin{array}{c}\text { US } \\
3962482\end{array}$ & $\begin{array}{l}\text { Clear, elastic, water gels } \\
\text { based on carrageenan }\end{array}$ & 08 jun. 1976 & $\begin{array}{l}\text { Comer, F. W \& } \\
\text { Strong, C. H.G. }\end{array}$ \\
\hline & $\begin{array}{c}\text { US } \\
4096327\end{array}$ & Modified kappa-carrageenan & 20 jun. 1978 & Guiseley, K. B. \\
\hline & $\begin{array}{c}\text { US } \\
4307124\end{array}$ & $\begin{array}{l}\text { Composition and method for } \\
\text { preparing dessert gel }\end{array}$ & 22 dez. 1981 & $\begin{array}{l}\text { Moirano, A. L. } \\
\text { e Mountainside, } \\
\text { N.J. }\end{array}$ \\
\hline & $\begin{array}{c}\text { US } \\
4443486\end{array}$ & $\begin{array}{l}\text { Modified extractive of } \\
\text { Eucheuma cottonii seaweed } \\
\text { and composition containing }\end{array}$ & 17 abr. 1984 & Guiseley, K. B. \\
\hline
\end{tabular}




\begin{tabular}{|c|c|c|c|c|}
\hline & & same & & \\
\hline & $\begin{array}{c}\text { US } \\
4457908\end{array}$ & $\begin{array}{l}\text { Stabilization of carrageenan- } \\
\text { containing toothpaste }\end{array}$ & 03 jul. 1984 & Scott, G. V. \\
\hline & $\begin{array}{c}\text { US } \\
4474818\end{array}$ & $\begin{array}{ll}\text { Increasing viscosity } & \text { of } \\
\text { carrageenan-containing } & \\
\text { compositions } & \text { with } \\
\text { microwave radiation } & \\
\end{array}$ & 02 out. 1984 & Scott, G. V. \\
\hline & $\begin{array}{c}\text { US } \\
4473988\end{array}$ & Dentifrice packaging process & 02 out. 1984 & Scott, G. V. \\
\hline & $\begin{array}{c}\text { US } \\
5002934\end{array}$ & $\begin{array}{l}\text { Aqueous gel comprising } \\
\text { carrageenan }\end{array}$ & 26 mar. 1991 & $\begin{array}{l}\text { Brown, C. R., e } \\
\text { Norton, I. T. }\end{array}$ \\
\hline & $\begin{array}{c}\text { US } \\
5502179\end{array}$ & $\begin{array}{l}\text { Carrageenan product and a } \\
\text { method of producing same }\end{array}$ & 26 mar. 1996 & Larsen, P. F. \\
\hline & $\begin{array}{c}\text { US } \\
6187293\end{array}$ & $\begin{array}{l}\text { Process for making } \\
\text { toothpaste } \\
\text { of carrageenan }\end{array}$ & 13 fev. 2001 & Ballard, A. D. \\
\hline & $\begin{array}{c}\text { US } \\
6387354\end{array}$ & $\begin{array}{l}\text { Semi-refined carrageenan } \\
\text { dentifrice binder }\end{array}$ & 14 maio 2002 & $\begin{array}{l}\text { Bixler, H. J., e } \\
\text { Sanchez- } \\
\text { Zaballero, G. }\end{array}$ \\
\hline & $\begin{array}{c}\text { US } \\
6458405\end{array}$ & $\begin{array}{l}\text { Gel products with } \\
\text { carrageenan }\end{array}$ & 01 out. 2002 & $\begin{array}{l}\text { Roy, S., } \\
\text { Ryan, A. L. }\end{array}$ \\
\hline & $\begin{array}{c}\text { US } \\
6479649\end{array}$ & $\begin{array}{l}\text { Production of carrageenan } \\
\text { and carrageenan products }\end{array}$ & 12 nov. 2002 & $\begin{array}{l}\text { Tsai, A. G., et } \\
\text { al. }\end{array}$ \\
\hline & $\begin{array}{c}\text { US } \\
6663910\end{array}$ & $\begin{array}{l}\text { Method of preparing food } \\
\text { products with carrageenan }\end{array}$ & 16 dez. 2003 & $\begin{array}{l}\text { Roy, S., } \\
\text { Ryan, }\end{array}$ \\
\hline & $\begin{array}{c}\text { US } \\
7018635\end{array}$ & Semi-refined carrageenan & 28 mar. 2006 & $\begin{array}{l}\text { Tsai, A. G., et } \\
\text { al. }\end{array}$ \\
\hline & $\begin{array}{l}\text { Indian } \\
\text { patent } \\
215567\end{array}$ & A toothpaste composition & 14 mar. 2008 & $\begin{array}{l}\text { Randive, V. B., } \\
\text { e Gadkari, V. } \\
\text { K. }\end{array}$ \\
\hline & $\begin{array}{c}\text { EP } \\
2181115\end{array}$ & $\begin{array}{l}\text { Process for treatment of } \\
\text { kappa carrageenan }\end{array}$ & 05 maio 2010 & Trudso, J. E. \\
\hline & $\begin{array}{c}\text { EP } \\
2181116\end{array}$ & Carrageenan & 05 maio 2010 & Trudso, J. E. \\
\hline & $\begin{array}{c}\text { EP } \\
2183264\end{array}$ & Kappa carrageenan & 12 maio 2010 & Trudso, J. E. \\
\hline & $\begin{array}{c}\text { US } \\
7816341\end{array}$ & $\begin{array}{l}\text { Homogeneous, } \\
\text { thermoreversible gel } \\
\text { containing reduced viscosity } \\
\text { carrageenan and products } \\
\text { made therefrom }\end{array}$ & 19 out. 2010 & $\begin{array}{l}\text { Sewell, C. J., } \\
\text { Riley, P. J., e } \\
\text { Blakemore, W. } \\
\text { R. }\end{array}$ \\
\hline Agar & \begin{tabular}{|l|} 
US \\
4780534
\end{tabular} & $\begin{array}{l}\text { Process for producing agar- } \\
\text { agar from an algae extraction }\end{array}$ & 25 out. 1988 & $\begin{array}{l}\text { Lebbar, } \\
\text { R., Delmas, M., }\end{array}$ \\
\hline
\end{tabular}




\begin{tabular}{|c|c|c|c|}
\hline & juice & & e Gaset, A. \\
\hline $\begin{array}{l}\text { US } \\
3901873\end{array}$ & $\begin{array}{l}\text { Process for the production } \\
\text { of agar from a redalga }\end{array}$ & 26 ago. 1975 & $\begin{array}{l}\text { Shuji, } \\
\text { D., Tomiji, S., e } \\
\text { Shigenobu, T. } \\
\end{array}$ \\
\hline $\begin{array}{l}\text { EP } \\
0598141\end{array}$ & $\begin{array}{l}\text { Production process of quick } \\
\text { soluble agar }\end{array}$ & 12 mar. 1997 & $\begin{array}{l}\text { Lebbar, } \\
\text { T., Lebbar, } \\
\text { R., e Riad, A. }\end{array}$ \\
\hline $\begin{array}{l}\text { US } \\
3860573\end{array}$ & $\begin{array}{l}\text { Method for cross-linking } \\
\text { agarose or agar }\end{array}$ & 14 jan. 1975 & $\begin{array}{l}\text { Juhani, H. E., e } \\
\text { Maija, T. A. }\end{array}$ \\
\hline $\begin{array}{l}\text { US } \\
2211338\end{array}$ & Preparation of esters of agar & 13 ago. 1940 & $\begin{array}{l}\text { Emerson, J., e } \\
\text { Malm Carl J }\end{array}$ \\
\hline $\begin{array}{l}\text { US } \\
3410704 \\
\end{array}$ & $\begin{array}{l}\text { Denture adhesive consisting } \\
\text { of pectin andagar }\end{array}$ & 12 nov. 1968 & Beachner, C. E. \\
\hline $\begin{array}{l}\text { US } \\
1201742\end{array}$ & $\begin{array}{l}\text { Agar-agar biscuit and } \\
\text { method of making the same. }\end{array}$ & 17 out. 1916 & Keyser, T. S. \\
\hline $\begin{array}{l}\text { US } \\
3929694\end{array}$ & $\begin{array}{l}\text { Clear adhesive applicator } \\
\text { crayon comprisingagar and } \\
\text { polyacrylamide }\end{array}$ & 30 dez. 1975 & $\begin{array}{ll}\text { Columbus, } & \text { P. } \\
\text { S. }\end{array}$ \\
\hline $\begin{array}{l}\text { US } \\
3416998\end{array}$ & $\begin{array}{l}\text { Method of detecting or } \\
\text { classifying microorganisms } \\
\text { using agar reagent sheets }\end{array}$ & 17 dez. 1968 & $\begin{array}{l}\text { Streitfeld, M. } \\
\text { M. }\end{array}$ \\
\hline $\begin{array}{l}\text { US } \\
4291025\end{array}$ & Agar gel topical dressing & 22 set. 1981 & Pellico, M. A. \\
\hline $\begin{array}{l}\text { US } \\
3631575\end{array}$ & Multiwell agar gel punch & 04 jan. 1972 & $\begin{array}{ll}\text { Walter } & \text { Farris, } \\
\text { W. } & \\
\end{array}$ \\
\hline $\begin{array}{l}\text { US } \\
4052264\end{array}$ & Agar-base gelling products & 04 out. 1977 & Kragen, H. \\
\hline $\begin{array}{l}\text { CN } \\
102771514\end{array}$ & Seed treating agente & 14 nov. 2012 & Xieqiong, Z. \\
\hline $\begin{array}{l}\text { US } \\
3425832 \\
\end{array}$ & $\begin{array}{l}\text { Purified agar silver halide } \\
\text { photographic processing web }\end{array}$ & 04 fev. 1969 & $\begin{array}{l}\text { Bornemisza, E. } \\
\text { S. }\end{array}$ \\
\hline $\begin{array}{l}\text { WO } \\
201311308 \\
6\end{array}$ & $\begin{array}{l}\text { Filme polimérico de ágar } \\
\text { hidrossoluvel e seu processo } \\
\text { de obtenção }\end{array}$ & 08 ago. 2013 & Yara, R., et al. \\
\hline $\begin{array}{l}\text { US } \\
6322814\end{array}$ & $\begin{array}{l}\text { Manufacture of and uses for } \\
\text { low molecular weight agars } \\
\text { and agaroids }\end{array}$ & 27 nov. 2001 & Miller, I. J. \\
\hline $\begin{array}{l}\text { US } \\
1163175\end{array}$ & Cereal preparation & 07 dez. 1915 & Rullman, W. A. \\
\hline $\begin{array}{l}\text { US } \\
6579694\end{array}$ & $\begin{array}{l}\text { Agar medium for the growth } \\
\text { of } \quad \text { Mycobacterium } \\
\text { tuberculosis }\end{array}$ & 17 jun. 2003 & $\begin{array}{l}\text { Heifets, L., e } \\
\text { Sanchez, T. }\end{array}$ \\
\hline US & Extraction and preparation & 20 abr. 1948 & $\begin{array}{l}\text { Joseph, F. B., e } \\
\text { Philip, S. P. }\end{array}$ \\
\hline
\end{tabular}




\begin{tabular}{|c|c|c|c|c|}
\hline & 2439964 & \multicolumn{3}{|l|}{ of agar } \\
\hline & $\begin{array}{l}\text { WO } \\
201312506 \\
4\end{array}$ & Semi-solidified nutriente & 29 ago. 2013 & $\begin{array}{l}\text { Tani, Y., e } \\
\text { Nakashima, H. }\end{array}$ \\
\hline & $\begin{array}{l}\mathrm{CN} \\
203013535\end{array}$ & $\begin{array}{l}\text { Electrolytic capacitor } \\
\text { isolation componente }\end{array}$ & 19 jun. 2013 & Xiaome, L. \\
\hline & $\begin{array}{l}\mathrm{EP} \\
0389700\end{array}$ & Soft agar capsules & 03 out. 1990 & $\begin{array}{l}\text { Goto, }{ }^{\text {H., }} \\
\text { e Kondo, T. }\end{array}$ \\
\hline & $\begin{array}{l}\mathrm{EP} \\
2633848\end{array}$ & $\begin{array}{ll}\text { Natural } & \text { multiphase } \\
\text { cosmetics } & \end{array}$ & 04 set. 2013 & $\begin{array}{l}\text { Skwarek, M.., e } \\
\text { Skwarek, M. }\end{array}$ \\
\hline \multirow[t]{6}{*}{ Alginato } & $\begin{array}{l}\text { WO } \\
201200669 \\
8\end{array}$ & $\begin{array}{lrr}\text { Biocompósito, } & \text { usos } \\
\text { relacionados, processo para a } \\
\text { produção do } & \text { mesmo, e } \\
\text { método de } & \text { liberação } \\
\text { controlada de } & \text { substância } \\
\text { antimicrobiana } & \\
\end{array}$ & 19 jan. 2012 & $\begin{array}{l}\text { Leão, M. H. M. } \\
\text { R., Souza, C. } \\
\text { A. S., e Rossi, } \\
\text { A. M. }\end{array}$ \\
\hline & $\begin{array}{l}\text { WO } \\
201207914 \\
2\end{array}$ & $\begin{array}{l}\text { Composição biopolimérica } \\
\text { para o encapsulamento de } \\
\text { células, método de produção } \\
\text { de uma composição } \\
\text { biopolimérica para o } \\
\text { encapsulamento de células, } \\
\text { método para promover a } \\
\text { citoproteção de células e uso } \\
\text { de uma composição } \\
\text { biopolimérica para o } \\
\text { encapsulamento de células }\end{array}$ & 21 jun. 2012 & $\begin{array}{l}\text { Lisboa, A. C. } \\
\text { V. C., et al. }\end{array}$ \\
\hline & \begin{tabular}{|l} 
WO \\
201308796 \\
6
\end{tabular} & $\begin{array}{l}\text { Uso de alginatos en } \\
\text { velocimetría por imágenes de } \\
\text { partículas y procedimiento } \\
\text { para medir la velocidad de } \\
\text { un fluido }\end{array}$ & 20 jun. 2013 & $\begin{array}{l}\text { Düzgün, N. E., } \\
\text { e Peña, A. V. }\end{array}$ \\
\hline & \begin{tabular}{|l} 
WO \\
200900095 \\
5
\end{tabular} & $\begin{array}{l}\text { Micropartículas de alginato } \\
\text { modificado con rgd como } \\
\text { sistema de liberación de } \\
\text { fármacos }\end{array}$ & 31 dez. 2008 & $\begin{array}{l}\text { Arroyo, G. O., } \\
\text { Muñoz, J. L. P., } \\
\text { e Martín, R. M. } \\
\text { H. }\end{array}$ \\
\hline & $\begin{array}{l}\text { WO } \\
201010315 \\
0\end{array}$ & $\begin{array}{l}\text { Biocatalizador inmovilizado } \\
\text { basado en alginato para la } \\
\text { biotransformación } \\
\text { carbohidratos }\end{array}$ & 16 set. 2010 & $\begin{array}{l}\text { Fernández- } \\
\text { Arrojo, L., et } \\
\text { al. }\end{array}$ \\
\hline & \begin{tabular}{|l} 
WO \\
200906311
\end{tabular} & $\begin{array}{l}\text { Use of microparticles for } \\
\text { vaccines and the release of }\end{array}$ & 22 maio 2009 & $\begin{array}{l}\text { Hernandez, M. } \\
\text { R. M., Igartua, }\end{array}$ \\
\hline
\end{tabular}




\begin{tabular}{|c|c|c|c|c|}
\hline & \multirow{2}{*}{\begin{tabular}{|l|}
6 \\
WO \\
200910968 \\
1 \\
\end{tabular}} & biologically active molecules & & \multirow{2}{*}{\begin{tabular}{|l|} 
O. M., e \\
Pedraz, M. J. \\
Ferrer, J. L. \\
\end{tabular}} \\
\hline & & $\begin{array}{l}\text { Preparation of gelled food } \\
\text { products from pulp fruit and } \\
\text { facility used for same }\end{array}$ & 11 set. 2009 & \\
\hline & $\begin{array}{l}\text { US } \\
4948575\end{array}$ & $\begin{array}{l}\text { Alginate hydrogel foam } \\
\text { wound dressing }\end{array}$ & 14 ago. 1990 & $\begin{array}{l}\text { Cole, S.M., e } \\
\text { Garbe, J. E. }\end{array}$ \\
\hline \multirow[t]{11}{*}{ Fucanas } & $\begin{array}{l}\text { EP } \\
2643356\end{array}$ & $\begin{array}{ll}\text { Process } & \text { for } \\
\text { isolating fucoidan and } & \\
\text { laminarin from } & \text { live, } \\
\text { harvested seaweed } & \end{array}$ & 02 out. 2013 & $\begin{array}{l}\text { Hjelland, F., } \\
\text { Andersen, A. } \\
\text { H., e } \\
\text { Yang, H. S. }\end{array}$ \\
\hline & \begin{tabular}{|l} 
EP \\
2121767
\end{tabular} & $\begin{array}{l}\text { Process methods } \\
\text { for fucoidan purification } \\
\text { from seaweed extracts }\end{array}$ & 09 abr. 2014 & $\begin{array}{l}\text { Shaklee, P. } \\
\text { N., et al. }\end{array}$ \\
\hline & $\begin{array}{l}\text { EP } \\
1234568\end{array}$ & $\begin{array}{l}\text { Use of fucoidan as effective } \\
\text { hair restoring ingrediente }\end{array}$ & 23 jul. 2008 & $\begin{array}{l}\text { Shigetoshi, M., } \\
\text { et al. }\end{array}$ \\
\hline & $\begin{array}{l}\text { US } \\
7749545\end{array}$ & $\begin{array}{l}\text { Fucoidan compositions and } \\
\text { methods for dietary and } \\
\text { nutritional supplements }\end{array}$ & 06 jul. 2010 & Mower, T. E. \\
\hline & \begin{tabular}{|l|}
$\mathrm{CN}$ \\
103230411
\end{tabular} & $\begin{array}{l}\text { Application } \\
\text { of fucoidan polysaccharide } \\
\text { sulfate in preparing drug for } \\
\text { preventing and/or treating } \\
\text { diabetic cardiomyopathy }\end{array}$ & 07 ago. 2013 & Dali, L., et al. \\
\hline & $\begin{array}{l}\text { WO } \\
200609118 \\
0\end{array}$ & $\begin{array}{l}\text { Fucoidan multiparticulate } \\
\text { drug carrier systems }\end{array}$ & 31 ago. 2006 & Sezer, A. D. \\
\hline & $\begin{array}{l}\text { US } \\
201200651 \\
58\end{array}$ & $\begin{array}{l}\text { Fucoidan having antitumor } \\
\text { activity }\end{array}$ & 15 mar. 2012 & $\begin{array}{l}\text { Okamoto, Y., et } \\
\text { al. }\end{array}$ \\
\hline & $\begin{array}{l}\text { US } \\
6573250\end{array}$ & $\begin{array}{l}\text { Food or beverage additive } \\
\text { containing fucoidanand food } \\
\text { and beverage } \\
\text { containing fucoidan }\end{array}$ & 03 jun. 2003 & $\begin{array}{l}\text { Umeda, U., et } \\
\text { al. }\end{array}$ \\
\hline & \begin{tabular}{|l|}
$\mathrm{CN}$ \\
103239472
\end{tabular} & $\begin{array}{l}\text { Novel medicinal application } \\
\text { of fucoidanpolysaccharide } \\
\text { sulfate }\end{array}$ & 14 ago. 2013 & DALI, L., et al. \\
\hline & \begin{tabular}{|l|} 
US \\
201103011 \\
19
\end{tabular} & $\begin{array}{l}\text { Pharmaceutical compositions } \\
\text { containingfucoidan for } \\
\text { stimulating and activating } \\
\text { osteogenesis }\end{array}$ & 08 dez. 2011 & $\begin{array}{l}\text { Kim, S. K., } \\
\text { e Cho, Y.S. }\end{array}$ \\
\hline & \begin{tabular}{|l|} 
US \\
200501297
\end{tabular} & Fucoidan-based health food & 16 jun. 2005 & $\begin{array}{l}\text { Fujii, M., Hou, } \\
\text { D. X., }\end{array}$ \\
\hline
\end{tabular}


A literatura tem descrito diversas propriedades biológicas atribuídas às carragenanas, tais como atividade anticoagulante e antitrombótica, antiviral, anti-tumor, imunomodulatória, antioxidante e anti-hiperlipêmica (BUCK et al., 2006; CAMPO et al., 2009; HAIJIN, XIAOLU e HUASHI, 2003; PRAJAPATI et al., 2014; ROSA, 1972; WIJESEKARA, PANGESTUTI e KIM, 2011; ZHOU et al., 2004).

As carragenanas são conhecidas pelas suas propriedades gelificantes, estabilizantes e emulsificantes, representando uma matéria-prima com qualidades variadas adequadas para uso em indústrias alimentícias, cosméticas e farmacêuticas. Apesar desse polissacarídeo não ter valor nutricional e nem serem digeridos ou absorvidos pelo sistema digestivo humano, tem sido amplamente utilizado na indústria de alimentos (PRAJAPATI et al., 2014; ROSA, 1972). São usados como aditivos em uma série de alimentos processados (McHUGH, 2003), dentre os quais:

- Produtos lácteos como queijo, sorvetes, chocolates a base de leite, leite UHT esterilizado, cremes, iogurtes;

- Alimentos à base de água como geleias ou gelatinas, cervejas (usadas na clarificação);

- Produtos de carne como presuntos, salcichas, hambúrguer, pedaços de frango ou peru pré-cozidos (melhorando a textura e maciez por reter água);

- Pode ser usado como substitutos de gordura em produtos cárneos com baixo teor de gordura, melhorando a maciez, suculência e sabor;

- Alimento enlatados para animais, pois a carne utilizada nesses alimentos é geralmente cortes de resíduos de abatedouro, que é cortada em pedaços menores, misturado com água, sabores, farinha de algas marinhas ( $\kappa$ - carragenana) e goma de alfarroba, enlatada e cozida.

Outros produtos que podem ser usados carragenana são gel ambientador para melhorar o odor e em creme dental - com função espessante (McHUGH, 2003). Em sistemas de biocatalisadores imobilizados também são usadas carragenanas. Nesta aplicação, a $\kappa$ carragenana é aplicada como meio para imobilizar enzimas ou células inteiras (McHUGH, 2003). Esses biocatalisadores imobilizados propiciam o uso de enzimas ou células por períodos prolongados através de processos contínuos ou semi-contínuos, industriais e biotecnológicos, sendo aplicados na produção de biosensores, produção de xarope de milho rico em frutose, produção contínua de L-aminoácidos com a enzima aminoacilase, produção de ácido 6-amino-penicilânico a partir de penicilina $\mathrm{G}$ ou V, acrilamida a partir de acrilonitrila, dentre outras (CARVALHO, CANILHA e SILVA, 2006).

$\mathrm{Na}$ indústria farmacêuticas, a carragenana é utilizada como excipientes de comprimidos (CAMPO et al., 2009), na produção de antibióticos tetraciclinas e clorotetraciclinas, na produção de antibióticos semi-sintéticos como os beta-lactâmicos, e produção de ácido Daspártico (PRAJAPATI et al., 2014).

Em medicina experimental, carragenana é frequentemente utilizada para induzir inflamação em testes de agentes anti-inflamatórios. O modelo de edema em pata de rato induzido por carragenana é um dos mais adotados para determinar a atividade antiinflamatória. Constitui um modelo animal simples e de rotina para avaliação da dor no local da inflamação, sem qualquer dano ou prejuízo para a pata inflamada, com a vantagem 
ainda de produzir resposta a doses abaixo do nível tóxico (PRAJAPATI et al., 2014; ROSA, 1972).

Algumas importantes aplicações biomédicas e farmacêuticas têm sido descritas na área de entrega de drogas. Li et al., (2014), em uma revisão sobre carragenanas e suas aplicações em entrega de drogas, verificou que este polissacarídeo não é utilizado apenas para a entrega de drogas pequenas e proteínas, mas também para a regeneração de tecidos com distribuição de biomacromoléculas terapêuticas e células.

Atualmente, a carragenana é utilizada principalmente como matriz de polímero na forma de comprimidos de liberação prolongada por via oral, como um auxiliar de extrusão para a produção de pellets e como um carreador/estabilizador em sistemas de micro/nanopartículas (LI et al., 2014).

É importante ressaltar que apesar de suas propriedades biológicas, tais como atividade antitumoral, efeitos imunomoduladores, anticoagulante e respostas inflamatórias serem reconhecidas, são necessárias maiores avaliações da segurança de carragenanas em algumas aplicações.

\section{Agaranas}

As agaranas, ou simplesmente ágar, são polissacarídeos lineares estruturalmente semelhantes às carragenanas, diferindo na estereoquímica na unidade $\mathrm{B}$ por possuir um resíduo de $\alpha$-L-galactose (figura 3), que também pode estar na forma de 3,6-anidro (CUNHA, DE PAULA e FEITOSA, 2009; FERREIRA, 2011). No entanto, nas agaranas ocorrem variações dessa estrutura básica através de certo grau de substituições tanto na unidade A quanto na B, com grupos sulfato, ésteres, metil ésteres, acetal de ácido pirúvico, 4-O-metil-L-galactose e/ou D-xilose e diferentes percentagens de 3,6-anidrogalactose (USOV, 2011).

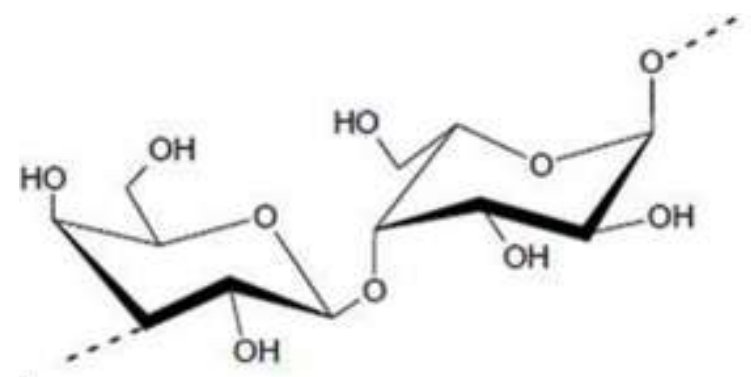

Figura 3. Estrutura básica da unidade dimérica de repetição das agaranas. Fonte: FERREIRA, 2011.

As agaranas são extraídas de um grande número de algas vermelhas da classe Rhodophyceae, principalmente no gênero Laurencia, Gracilaria e Gelidium. Sua presença já foi relatada em espécies como Laurencia flexilis, L. pinatifida, L. papillosa, L. crcuciata, L. pedicularioides, L. majuscula, L. nipponica, L. filiformis, L. obtusa, L. aldingensis, Gracilaria gracilis, G. lemaneiformis, G. vermiculophylla, Gelidium purpurascens, Gelidium pacificum e ainda em Palisada flagellifera, Polysiphonia nigrescens, Gymnogongrus torulosus e Grateloupia filicina (AKATSUKA e IWAMOTO, 1979; BOWKER e TURVEY, 1968; CANELÓN et al., 2014; ESTEVEZ, CIANCIA e CEREZO, 2001; FERREIRA, 2011; FERREIRA et al., 2012; LI et al., 2008; PRADO, CIANCIA e MATULEWICZ, 2008; RODRÍGUEZ et al., 2009; SIDDHANTA et al., 2002; USOV e 
ELASHVILI, 1991; VILLANUEVA et al., 2010a; VILLANUEVA et al., 2010b; YU et al., 2012; WHYTE e ENGLAR, 1981).

As agaranas consistem em uma mistura de uma fração neutra completamente cíclica chamada de agarose e uma fração aniônica que correspondem às agaropectinas (LI et al., 2008; MUTHUSWAMY et al, 2007). A agarose é industrialmente obtida principalmente a partir de algas marinhas das ordens Gracilariales e Gelidiales (CANELÓN et al., 2014). Agaropectina tem a mesma estrutura que a agarose, mas contém muitos grupos aniônicos, tais como sulfato, piruvato e glicuronato (RINAUDO, 2008).

O ágar, desde muito tempo, é conhecido por suas propriedades gelificantes. É solúvel em água quente, mas insolúvel em água fria, por isso sua extração é realizada a partir de algas marinhas cozidas (RINAUDO, 2008). Entretanto, algumas aplicações do ágar tem modificado essa característica. Foi desenvolvido um filme polimérico produzido à base de ágar, totalmente hidrossolúvel, a quente ou a frio, que pode ser usado como suporte para a incorporação de alimentos naturais, artificiais e/ou funcionais ou ainda na indústria farmacêutica, para veiculação de princípios ativos (UNIVERSIDADE FEDERAL DE PERNAMBUCO, 2013). Para tanto, o ágar foi modificado por reação a quente em meio ácido, o que incrementou a capacidade de dissolução do ágar em meio aquoso.

As aplicações de agarose e ágar descritos na literatura são principalmente na área farmacêutica, alimentícia e biotecnológica. São utilizadas em meios de separação e purificação como eletroforese em gel, cromatografia de grânulos de gel, cromatografia de exclusão de tamanho, em produtos de química fina, hormônios, enzimas, vacinas, suspensão para radiografar o trato gastrointestinal, dispositivos de liberação contínua, produção de moldes utilizados em odontologia, criminologia, substituto de gelatina e refeição vegetariana (RINAUDO, 2008).

A agarose é também amplamente empregada em microbiologia, sendo utilizada como meio de cultura para os microrganismos (bactérias e fungos) e para aplicações biotecnológicas (RINAUDO, 2008).

As possibilidades de aplicações do ágar na indústria alimentícia e farmacêutica são reconhecidas há muito tempo. Já foram utilizados ágar em formulações de um cereal nutritivo e facilmente digerido (WALTER AMES RULLMAN, 1915); em cosméticos naturais de duas fases, sob a forma de gel com emulsão rica em vários componentes naturais suspensos dentro, destinados especialmente para o tratamento da pele e do cabelo (PULANNA SP. ZO.O, 2013); e em cápsula macia e globular preparada à base de ágar, que podem ser aplicadas a produtos farmacêuticos, químicos, cosméticos, alimentos (FUJI CAPSULE KABUSHIKI KAISHA, 1990). Uma importante aplicação médica/farmacêutica do ágar consiste no desenvolvimento de um curativo tópico formulado com ágar para o revestimento de uma área de queimadura ou outro local da deficiência de pele (PELLICO,1981). Uma visão geral de patentes desse polissacarídeo consta na tabela 1 .

\section{Alginato}


Ácido algínico ou alginatos de algas são polissacarídeos aniônicos, lineares, composto por resíduos de ácido $\beta$-D-manurônico e ácido $\alpha$-L-gulurônico ligados em (1-4), arranjados como uma série de estruturas em bloco (GACESA, 1988). Estes podem ser homopoliméricas [poli ( $\beta$-D-manuronato) e poli ( $\alpha$-L-guluronato)] (figura 4) ou heteropolimérica, aproximando-se de uma sequência alternada (GACESA, 1988). Sua estrutura é comumente representada pelo modelo casca de ovo.

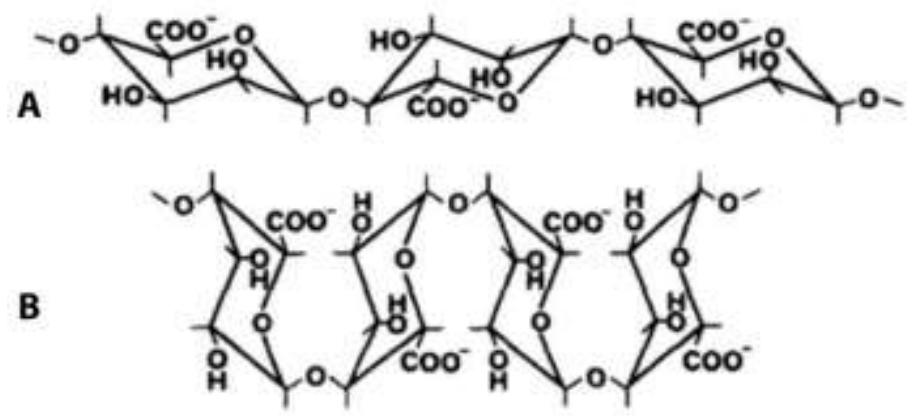

Figura 4. Estrutura e conformação das cadeias de poli ( $\beta$-D-manuronato) (A) e poli ( $\alpha$-L-guluronato) (B). Fonte: GACESA, 1988.

Uma importante propriedade do alginato é a capacidade de formar géis na presença de certos cátions divalentes (ou multivalentes), em particular de $\mathrm{Ca}^{2+}$, devido à sua estrutura em blocos polianiônicos (GACESA, 1988).

As propriedades físicas do gel dependerão da proporção de ácidos urônicos nas cadeias de polissacarídeos, de modo que alginatos ricos em de L-guluronato formam géis fortes, mas os ricos em D-manuronatos são mais fracos, porém com a vantagem de serem mais flexíveis (GACESA, 1988). Essa variação pode ser entendida segundo o modo como os cátions se ligam às várias estruturas em blocos. Todas as estruturas em bloco formam ligações iônicas intermoleculares com cátions di ou multivalentes, porém as regiões de poliguluronato também são capazes de quelar os íons de metais devido ao arranjo espacial dos átomos do anel de oxigénio e hidroxila e, assim, formar um tipo muito mais forte de interação (DAVIS, VOLESKY e MUCCI, 2003; GACESA, 1988).

Os alginatos são extraídos das algas marrons, em particular das espécies Sargassum fluitans, sendo também relatado em Sargassum longifolium, Sargassum wightii e Sargassum tenerium, Sargassum vulgare, Ascophyllum nodosum, Fucus vesiculosus e Laminaria japônica (DAVIS, VOLESKY e MUCCI, 2003; FOUREST e VOLESKY, 1997, SOUSA et al., 2007). O alginato está presente na parede celular dessas algas pardas, contribuindo para a resistência da parede celular, mas também conferindo flexibilidade (DAVIS, VOLESKY e MUCCI, 2003).

Davis, Volesky e Mucci (2003), revisando a bioquímica de biossorção de metais pesados por algas marrons, relata que a biomassa dessas algas representam uma classe especialmente eficiente e resiliente de biosorventes em relação a outros tipos de biomassa e o polissacarídeo alginato é o principal responsável para a capacidade de troca iónica natural de algas marrons. A propriedade de biossorção, bem como o entendimento de seu mecanismo, tem chamado atenção pela capacidade de aplicação da biomassa de algas para sequestrar metais pesado de efluentes industriais ou para recuperar metais preciosos a partir de soluções de processamento. 
Tem sido efetivamente reconhecidas a aplicações dos alginatos nos domínios alimentícios, com uso em sorvetes, misturas para bolos, produtos lácteos, bebidas como cervejas e sucos; na indústria têxtil, tintas utilizadas nos processos de impressão são aperfeiçoadas com o uso do alginato, favorecendo a aderência e a deposição das mesmas sobre os tecidos; ainda na indústria de alimentos, os alginatos podem ser utilizados em filmes bioativos para cobertura de alimentos e na preparação de alimentos reestruturados onde pode ser utilizado em polpas de frutas, de vegetais e em carnes (FOOD INGREDIENTS BRASIL, 2013). Esse polissacarídeo foi aplicado em uma preparação de produtos alimentares gelificados a partir de polpa de fruta, consistindo de pérolas de gel texturizadas com um estado líquido interno (FERRER, 2009).

Entretanto, são nas áreas farmacêutica e biotecnológica que o uso de alginato tem se destacado atualmente, sobretudo como excipientes em sistemas de liberação de fármaco e sistemas imunogênicos (formulações de vacinas), curativos inteligentes que absorvem exsudatos, dente outras. Em sistemas de biocatalisadores imobilizados onde são usadas carragenanas, também são aplicáveis os alginatos (McHUGH, 2003). Várias patentes em alginato são mostradas na tabela 1 .

Vale ressaltar que os alginatos apresentam considerável atividade anti-tumoral em experimento animal. Sousa et al. (2007), investigando a atividade antitumoral in vivo de dois alginatos (SVHV e SVLV) com viscosidade diferentes, extraído de algas marrom Sargassum vulgare C. Agardh contra células de sarcomas 180 (Tumor de Crocker) transplantadas em camundongos, verificou que ambos os alginatos inibiram o crescimento de sarcoma 180 e que essa atividade antitumoral pode estar relacionada com propriedades imunomodulatórias.

\section{Fucanas}

Fucoidanos (heterofucanas) ou fucanas (homofucanas) são conceituadas na literatura como uma classe de polissacarídeos sulfatados, negativamente carregados, hidrossolúveis, encontrados na matriz extracelular de algas marrons, estruturados com L-fucose (figura 5), mas que frequentemente pode apresentar em sua estrutura outros açúcares, a saber, Dxilose, D-galactose e ácido D-glucurônico (CUMASHI et al., 2007; DUARTE et al., 2001; KIM, RIOUX e TURGEON, 2014).

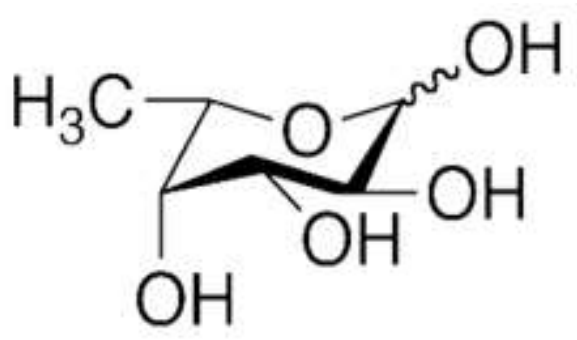

Figura 5. Estrutura da L-fucose. Fonte: Toronto Research Chemicals.

Sua presença já foi relatada em várias espécies de algas marrons, dentre as quais Fucus evanescens, Ascophyllum nodosum, Chorda filum, Laminaria saccharina, Laminaria digitata, Fucus serratus, Fucus distichus, Fucus spiralis, Cladosiphon okamuranus e Ascophyllum nodosum, Sargassum stenophyllum, Fucus vesiculosus, Adenocystis utricularis (BILAN et al., 2002; BLONDIN et al., 1996; CHIZHOV et al., 1999; 
CUMASHI et al., 2007; DUARTE et al., 2001; KIM, RIOUX e TURGEON, 2014; PONCE et al., 2003).

Esses polissacarídeos exibem atividades biológicas diversas, dentre as quais antiinflamatória, anticoagulante, antiangiogênica e antitumoral (CUMASHI et al., 2007), antiviral (PONCE et al., 2003), anti-complemento ou imunomodulatória (BLONDIN et al., 1996) e capacidade de inibição de $\alpha$-amilase e $\alpha$-glicosidase (KIM, RIOUX e TURGEON, 2014). A atividade inibitória das enzimas $\alpha$-amilase e $\alpha$-glicosidase, as quais degradam o amido da dieta em glicose, pode representar um método para controlar os níveis de açúcar no sangue, com potenciais benefícios para o controle da diabetes tipo 2 .

Os fucoidanos tem aplicações descritas nas áreas de alimentos, farmacêutica e cosmética (ver patentes na tabela 1). As pesquisas voltadas a desvendar suas atividades biológicas têm gerado aplicações importantes como a produção de medicamentos para tratamento clínico da cardiomiopatia diabética (UNIV CAPITAL MEDICAL SCIENCES, 2013a), da retinopatia diabética (UNIV CAPITAL MEDICAL SCIENCES, 2013b), ou para estimular e ativar a osteogênese (PUKYONG NATIONAL UNIVERSITY INDUSTRYACADEMIC COOPERATION FOUNDATION, 2011). Além disso, o uso em sistemas de veiculação de fármaco também é efetivo (SEZER, 2006).

São conhecidas ainda a utilização em suplementos alimentares/suplemento dietético na forma de bebidas, comprimidos, cápsulas, pós, e outros semelhantes (SAKURA PROPERTIES, LLC., 2010) ou em gel de fucoidano utilizado como um sistema de libertação de suplementos nutricionais, tais como vitaminas, dissolvidas ou suspensas (KEARL M., KEARL T., 2006).

\section{POLISSACARÍDEOS SULFATADOS: PROPRIEDADES E APLICAÇÕES}

Polissacarídeos sulfatados (PS) são descritos como macromoléculas bioativas onde alguns dos grupos hidroxila dos resíduos de açúcar são substituídos por grupamentos sulfato (PÉREZ-RECALDE et al., 2014). Os PS são macromoléculas que podem ser encontradas nos mais diversos organismos presentes na natureza, como nos tecidos animais, invertebrados e vegetais (BEZERRA NETO et al., 2008). As algas marinhas são a fonte mais importante de PS não animais (COSTA et al., 2010). O estudo dessas macromoléculas se justifica devido ao fato de possuírem varias atividades biológicas importantes, como anticoagulante, antitrombótica, imunoestimulante, dentre outras (Tabela 2), que despertam interesse em vários ramos da ciência médica e biotecnologia de organismos aquáticos (RODIGUES et al., 2009).

Provavelmente a bioatividade anticoagulante está entre as propriedades mais estudadas dos PS marinhos (RODIGUES et al., 2009) e foi relatada pela primeira vez para fucoidanos isolados de $F$. vesiculosus por Springer e colegas que detectaram a inibição da formação de coágulo de fibrina e atividade antitrombina (BERNARDI e SPRINGER, 1962; SPRINGER et al.; 1957). Desde então, os estudos sobre fucanas de várias algas revelaram atividades anticoagulantes e antitrombóticos e são discutidos em vários comentários recentes (JIAO et al., 2011; KUSAYKIN et al., 2008; LI et al., 2008; POMIN et al., 2008).

O estudo dessas macromoléculas é relacionado com a procura de novos fármacos que posam ser utilizados no tratamento e prevenção de trombose venosa profunda em póscirurgias e pós-parto, em pacientes com estado de hipercoagulopatia, ou sujeito à trombose 
causada por diferentes etiologias (ROCHA et al., 2004), e na substituição do uso da heparina, um PS mundialmente utilizado como agente anticoagulante e antitrombótico na prevenção e tratamento de trombose venosa, mais que pode causar significativos efeitos colaterais (BEZERRA NETO et al., 2008).

Tabela 2: Atividades biológicas de polissacarídeos sulfatados de algas marinhas.

\begin{tabular}{|c|c|c|}
\hline ATIVIDADE & FONTE & REFERENCIAS \\
\hline Anticoagulante & 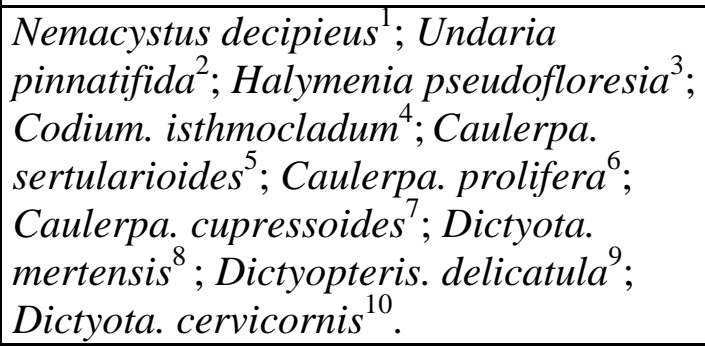 & $\begin{array}{l}\text { Kitamura et al., } 1992^{1} \text {; } \\
\text { Kim et al., 2010; } \\
\text { Rodrigues et al., } 2009^{3} \text {; } \\
\text { Costa et al., } \\
2010^{4,5,6,7,8,9,10 .}\end{array}$ \\
\hline Antioxidante & $\begin{array}{l}\text { Dictyota. cervicornis; Dictyopteris. } \\
\text { delicatula; Dictyota. menstruallis; } \\
\text { Dictyota. mertensis; Sargassum. } \\
\text { filipendula; Spatoglossum. schroederi; } \\
\text { Gracilaria. caudata } ; \text {, Caulerpa. } \\
\text { cupressoides; Caulerpa. prolifera; } \\
\text { Caulerpa. sertularioides; Codium. } \\
\text { isthmocladum. }\end{array}$ & Costa et al., 2010. \\
\hline Imunoestimulante & $\begin{array}{l}\text { Furcellaria lumbricalis }{ }^{1} ; \text { Solieria } \\
\text { chordalis }^{2} .\end{array}$ & $\begin{array}{l}\text { Yang et al., 2011 } \\
\text { Bondu et al., 2010 }\end{array}$ \\
\hline Antivenenosa & Botryocladia occidentalis. & Toyama et al., 2010. \\
\hline Antiviral & $\begin{array}{l}\text { Pelvetia canaliculata }^{1} \\
\text { Undaria pinnatifida }^{2}\end{array}$ & $\begin{array}{l}\text { Klarzynski et al., } \\
2003^{1} \text {; Hemmingson et } \\
\text { al., } 2006^{2} .\end{array}$ \\
\hline Antitumoral & Chondrus ocellatus. & Mou et al., 2003. \\
\hline Antitrombótica & Ascophyllum nodosum ${ }^{1}$; Ecklonia cava ${ }^{2}$. & $\begin{array}{l}\text { Colliec-Jouault et al., } \\
\text { 2003 }{ }^{1} \text {; Athukorala et } \\
\text { al., } 2006^{2} \text {. }\end{array}$ \\
\hline Angiogenese & Ascophyllum nodosum. & Matou et al., 2002. \\
\hline Cardioproteção & Cladosiphon okamuranus TOKIDA. & Thomes et al., 2010. \\
\hline $\begin{array}{l}\text { Proteção da mucosa } \\
\text { gástrica }\end{array}$ & Cladosiphon okamuranus TOKIDA. & Thomes et al., 2010. \\
\hline Neuroproteção & Laminaria japonica. & Luo et al., 2010. \\
\hline
\end{tabular}

Com a constatação da propriedade anticoagulante presente nos PS, esse tema tornou-se alvo de estudo com as mais diversas espécies de algas, e com utilização de variadas técnicas de extração. Estudos com PS de algas têm demonstrado que suas estruturas variam de espécies para espécies e, às vezes, em diferentes partes da mesma planta (ALVES, 2000; DIETRICH et al., 1995; HAROUN-BOUHEDJA et al., 2000). A complexidade na estrutura desses compostos é devido às muitas possibilidades de ligações entre os monossacarídeos e a distribuição de grupamentos sulfato.

Costa et al. (2010) realizaram um estudo com PS de 11 espécies de algas marinhas tropicais (uma espécie comestível de Rhodophyta, seis espécies de Phaeophyta e quatro espécies de Chlorophyta) coletadas no litoral da cidade de Natal-RN, e avaliaram suas 
atividades anticoagulante, antioxidante e antiproliferativa in vitro. Nos testes para avaliar a atividade anticoagulante, o tempo de tromboplastina parcial ativada (TTPA), que avalia a via intrínseca da coagulação, sete algas apresentaram atividade anticoagulante. No tempo de protrombina de (PT), que avalia a via extrínseca da coagulação, a apenas Caulerpa cupresoides mostrou atividade anticoagulante. Todas as espécies coletadas apresentaram atividades antioxidantes. A eficácia antiproliferativa foi positivamente correlacionada com o teor de sulfato.

A avaliação dos resultados encontrados por Costa et al. (2010), demonstram a importância do estudo e pesquisa dos PS de algas marinhas, e que pesquisas nessa vertente ainda podem ser muito exploradas.

Com objetivo de avaliar algumas características dos PS isolados da alga Halymenia pseudofloresia e o seu potencial anticoagulante Rodrigues et al. (2009) realizaram um trabalho utilizando três extrações sucessivas de PS de H. pseudofloresia onde observou-se que os rendimentos sofreram decréscimos marcantes no decorrer das extrações. As extrações foram realizadas por metodologias distintas, tais como enzimáticos, ácidos e aquosos (ATHUKORALA et al., 2007; BEZERRA-NETO, 2005; FARIAS et at., 2000; PERCIVAL e McDOWELL, 1967; ZHANG et al., 2008). As variações de rendimento podem ser justificadas pelo uso de diferentes metodologias.

A espécie apresentou frações com atividade anticoagulante, onde as extrações consecutivas resultaram em alterações dos valores de TTPA. Foi observado um aumento nos valores de TTPA, de maneira que a maioria das frações de $H$. pseudofloresia superou o rendimento do padrão de heparina utilizado. Quando ocorre um prolongamento significativo no TTPA sugere-se uma inibição da via intrínseca e/ou comum da cascata de coagulação (ATHUKORALA et al., 2007; ZHANG et al., 2008).

Os resultados do estudo em questão sugerem que é possível obter PS com diferentes atividades anticoagulantes utilizando extrações consecutivas do mesmo material. No entanto, as extrações sucessivas podem modificar acentuadamente a atividade anticoagulante, possivelmente em razão da mudança da conformação estrutural dessas macromoléculas.

\section{O MERCADO DE POLISSACARÍDEOS DE ALGAS NO BRASIL}

Cunha, de Paula e Feitosa (2009), em uma revisão sobre polissacarídeos da biodiversidade brasileira, fez um levantamento sobre importação e a exportação da vários polissacarídeos do período de 2003 a 2007 e observou que os produtos mais importados é celulose, um polissacarídeo de plantas, e seus derivados; a carragenana também está destaque, porém a importação de ágar é pequena, o que pode ser atribuídos aos altos preços dos polissacarídeos e algas. Similarmente, a exportação de polissacarídeo de alga foi irrisória, tendo apenas alguma exportação de ácido algínico e carragenana registrada. Entretanto, para uma visão mais sólida desse panorama econômico do mercado das algas no Brasil atualmente é necessário uma avaliação de dados mais recentes.

Os principais produtores de algas marinhas são os chineses e japoneses. Os Estados Unidos e a Noruega vêm em seguida. No Brasil, a exploração em maior escala com fins comerciais se resume à coleta de algas vermelhas (Gracilaria e Hypnea) no litoral do nordeste, sobretudo entre os estados do Ceará e da Paraíba (VIDOTTI e ROLLEMBERG, 2004). 


\section{CONSIDERAÇÕES FINAIS}

Há uma grande multiplicidade de espécies de algas com aplicações diversificadas em vários países no mundo, na indústria alimentícia e farmacêutica, cosmética, agricultura. Entretanto, vê-se que é preciso tornar mais robusto e significativo os recursos científicos, tecnológicos e financeiros, bem como atenuar a distância entre pesquisas em polissacarídeos de algas e produção e exploração no mercado.

\section{REFERÊNCIAS BIBLIOGRÁFICAS}

AKATSUKA, I.; IWAMOTO, K. Histochemical localization of agar and cellulose in the tissue of Gelidium pacificum (Gelidiaceae, Rhodophyta). Botanica marina, v. 22, n. 6, p. 367-370, 1979.

ALVES, L. G. Polissacarídeos ácidos presentes no folíolo, talo e flutuador da alga marinha Sargassum vulgare. 2000. 86 f. Dissertação (Programa de Pós-graduação em Bioquímica). Departamento de Bioquímica - Universidade Federal do Rio Grande do Norte-UFRN, Natal, 2000.

ATHUKORALA, Y.; JUNG, W. K.; VASANTHAN, T.; JEON, Y. J. An anticoagulative polysaccharide from an enzymatic hydrolysate of Ecklonia cava. Carbohydrate Polymers, v. 66, p. 184-191, 2006.

ATHUKORALA, Y.; LEE, K. W.; KIM, S. K.; JEON, Y. J. Anticoagulant activity of marine green and brown algae collected from Jeju Island in Korea. Bioresource Tecnology, v. 98, n. 09, p. 1711-1716, 2007.

BERNARDI, G.; SPRINGER, G. F. Properties of highly purified fucan. J. Biol. Chem, v. 237, p. 75-80, 1962.

BEZERRA NETO, J. T. B.; RODRIGUES, J. A. G.; PONTES, G. C.; FARIAS, W. R. L. Polissacarídeos sulfatados da alga Caulerpa sertularioides (GMEL.) Howe: Análise de metodologias de precipitação. Rev. Bras. Enga. Pesca, v. 3, n. 2, p. 50-62, 2008.

BEZERRA-NETO, J. T. B. Extração, fracionamento, purificação e atividade anticoagulante dos polissacarídeos sulfatados da alga marinha verde Caulerpa sertularioides (Caulerpales, Caulerpaceae). 2005. 29 f. Monografia (Graduação em Engenharia de Pesca) - Universidade Federal do Ceará, Fortaleza.

BILAN, M. I.; GRACHEV, A. A.; USTUZHANINA, N. E.; SHASHKOV, A. S.; NIFANTIEV, N. E.; USOV, A. I. Structure of a fucoidan from the brown seaweed Fucus evanescens C.Ag. Carbohydrate Research, v. 337, p. 719-730, 2002.

BLONDIN, C.; CHAUBET, F.; NARDELlA, A.; SINQUIN, C; JOZEFONVICZ, J. Relations between chemical characteristics and anticomplementary activitv of fucans. Biomaterialsl, v. 7, p. 597-403, 1996.

BONDU, S.; DESLANDES, E.; FABRE, M. S.; BERTHOU, C.; GUANGLI, Y. Carrageenan from Solieria chordalis (Gigartinales): Structural analysis and immunological activities of the low molecular weight fractions. Carbohydrate Polymers, v. 81, p. 448-460, 2010.

BOWKER, D. M.; TURVEY, J. R. Water-soluble Polysaccharides of the Red Alga Laurencia pinnatifida. Part 1. Constituent Units. J. Chem. SOC., p. 983-988, 1968. 
BUCK, C. B.; THOMPSON, C. D.; ROBERTS, J. N.; MÜLlER, M.; LOWY, D. R.; SCHILLER, J. T. Carrageenan is a potent inhibitor of Papillomavirus Infection. PLoS Pathogens, v. 2, p. 671-680, 2006.

CAMPO, V. L.; KAWANO, D. F.; SILVA JR., D. B.; CARVALHO, I. Carrageenans: Biological properties, chemical modifications and structural analysis- A review. Carbohydrate Polymers, v. 77, p. 167-180, 2009.

CANELÓN, D. J.; CIANCIA, M.; SUÁREZ, A. I.; COMPAGNONE, R. S.; \& MATULEWICZ, M. C. Structure of highly substituted agarans from the red seaweeds Laurencia obtusa and Laurencia filiformis. Carbohydrate polymers, v. 101, p. 705-713, 2014.

CARVALHO, W.; CANILHA, L.; SILVA, S. S. Uso de biocatalisadores imobilizados: uma alternativa para a condução de bioprocessos. Revista Analytica, n. 23, p. 70-80, 2006.

CHIOVITTI, A.; BACIC, A.; CRAIK, D. J.; KRAFT, G. T.; LIAO, M. L.; FALSHAW, R.; FURNEAUX, R. H. A pyruvated carrageenan from Australian specimens of the red alga Sarconema filiforme. Carbohydrate Research, v. 310, p. 77-83, 1998.

CHIZHOV, A. O.; DELL, A.; MORRIS, H. R.; HASLAM, S. M.; MCDOWELL, R. A.; SHASHKOV, A. S.; NIFANT'EV, N. E.; KHATUNTSEVA, E. A.; USOV, A. I. A study of fucoidan from the brown seaweed Chorda Filum. Carbohydrate Research, v. 320, p. 108-119, 1999.

COLliEC-JOUAUlT, S.; MILlET, J.; HELlEY, D.; SINQUIN, C.; FISCHER, A.M. Effect of low-molecularweight fucoidan on experimental arterial thrombosis in the rabbit and rat. J. Thromb. Haemost, v. 1, p. 1114-1115, 2003.

COSTA, L. S.; FIDELIS, G. P.; CORDEIRO, S. L.; OLIVEIRA, R. M.; SABRY, D. A.; CÂMARA, R. B. G.; NOBRE, L. T. D. B.; COSTA, M. S. S. P.; ALMEIDA-LIMA, J.; FARIAS, E. H. C.; LEITE, E.L.; ROCHA, H.A.O. Biological activities of sulfated polysaccharides from tropical seaweeds. Biomedicine \& Pharmacotherapy, v. 64, p. 21-28, 2010.

CUMASHI A.; USHAKOVA, N. A.; PREOBRAZHENSKAYA, M. E.; D'INCECCO, A.; PICCOLI, A.; TOTANI, L.; TINARI, N.; MOROZEVICH, G. E.; BERMAN, A. E.; BILAN, M. I.; USOV, A. I.; USTYUZHANINA, N. E.; GRACHEV, A. A.; SANDERSON, C. G. J.; KELLY, M.; RABINOVICH, G. A.; IACOBELLI, S.; NIFANTIEV, N. E. A comparative study of the anti-inflammatory, anticoagulant, antiangiogenic, and antiadhesive activities of nine different fucoidans from brown seaweeds. Glycobiology, v. 17, n. 5, p. 541-552, 2007.

CUNHA, P. L. R.; DE PAULA, R. C. M.; FEITOSA, J. P. A. Polissacarídeos da biodiversidade brasileira: uma oportunidade de transformar conhecimento em valor econômico. Quim. Nova, v. 32, n. 3, p. 649-660, 2009.

DAVIS, T. A.; VOLESKY, B.; MUCCI, A. A review of the biochemistry of heavy metal biosorption by brown algae. Water Research, v. 37, p. 4311-4330, 2003.

DEVILLÉ, C.; GHARBI, M.; DANDRIFOSSE, G.; PEULEN, O. Study on the effects of laminarin, a polysaccharide from seaweed, on gut characteristics. Journal of the Science of Food and Agriculture, v. 87, p. 1717-1725, 2007.

DIETRICH, C. P.; FARIAS, G. G. M.; ABREU, L. R. D.; LEITE, E. L.; SILVA, L. F.; NADER H. B. A new approach for characterization of polysaccharides from algae: 
Presence of four main acidic polysaccharides in three species of the class Phaeophycea. Plant Sci., v. 108, p. 143-153, 1995.

DUARTE, M. E.R.; CARDOSO, M. A.; NOSEDA, M. D.; CEREZO, A. S. Structural studies on fucoidans from the brown seaweed Sargassum stenophyllum. Carbohydrate Research, v. 333, p. 281-293, 2001.

ESTEVEZ, J. M.; CIANCIA, M.; CEREZO, A. S. DL-Galactan hybrids and agarans from gametophytes of the red seaweed Gymnogongrus torulosus. Carbohydrate research, v. 331, n. 1, p. 27-41, 2001.

FARIAS, W. R. L.; VALENTE, A. P.; PEREIRA, M. S.; MOURÃO, P. A. Structure and anticoagulant activity of sulfated galactans. Isolation of a unique sulfated galactan from the red alga Botryocladia occidentalis and comparison of its anticoagulant action with that of sulfated galactans from invertebrates. Journal of Biological Chemistry, v. 275, n. 38, p. 29299-29307, 2000.

FERREIRA, L. G. Estrutura química e atividade antiviral de polissacarídeos sulfatados obtidos de algas do complexo Laurencia (Ceramiales, Rhodophyta). 2011. 217 f. Tese (Doutorado em Bioquímica) - Departamento de Bioquímica e Biologia Molecular, Setor de Ciências Biológicas, Universidade Federal do Paraná, 2011.

FERREIRA, L. G.; NOSEDA, M. D.; GONÇALVES, A. G.; DUCATTI, D. R.; FUJII, M. T.; DUARTE, M. E. Chemical structure of the complex pyruvylated and sulfated agaran from the red seaweed Palisada flagellifera (Ceramiales, Rhodophyta). Carbohydrate research, v. 347, n. 1, p. 83-94, 2012.

FERRER, J. L., inventor; JORGE ISERN JARA, assignee (Espanha). Preparation of gelled food products from pulp fruit and facility used for same. WO 2009109681 A1, 6 mar. 2009, 11 set. 2009.

FMC Health and Nutrition (2014). Disponível em: http://www.fmcbiopolymer.com. Acessado em: 30.04.2014.

FOOD INGREDIENTS BRASIL. Os alginatos e suas múltiplas aplicações. Revista Fib, n. 26, p. 34-38, 2013. Disponivel em: http://www.revista-fi.com/materias/340.pdf. Acesso em: 27.04.14.

FOUREST, E.; VOLESKY, B.; Alginate Properties and Heavy Metal Biosorption by Marine Algae. Applied Biochemistry and Biotechnology, v. 67, p. 215-226, 1997.

FUJI CAPSULE KABUSHIKI KAISHA (Japan). Goto Hiroshi, Kondo Takashi. Soft agar capsules. EP 0389700 A1, 29 mar. 1989. 3 out. 1990.

GACESA, P. Alginates. Carbohydrate Polymers, v. 8, p. 161-182, 1988.

GIULIETTI, A. M.; HARLEY, R. M.; DE QUEIROZ, L. P.; WANDERLEY, M. G. L.; VAN DEN BERG, C. Biodiversidade e conservação das plantas no Brasil. Megadiversidade, v. 1, n. 1, p. 52-61, 2005.

GLICKSMAN, M. Utilization of seaweed hydrocolloids in the food industry. Twelfth International Seaweed Symposium Developments in Hydrobiology, v. 41, p. 31-47, 1987.

GRFER, C. W.; SHOMER, I.; GOLDSTEIN, M. E.; YAPHE, W. Analysis of carrageenan from Hypnea musciformis by using $\kappa$ - and $\mathrm{l}$-carrageenanases and ${ }^{13} \mathrm{C}-\mathrm{N}$.M.R. spectroscopy. Carbohydrate Research, v. 129, p. 189-196, 1984. 
GUO, J. H.; SKINNER, G. W.; HARCUM; W. W.; BARNUM, P. E. Pharmaceutical applications of naturally occurring water-soluble polymers. Pharmaceutical science \& technology today, v. 1, n. 6, p. 254-261, 1998.

HAIJIN, M.; XIAOLU, J.; HUASHI, G. A $\kappa$-carrageenan derived oligosaccharide prepared by enzymatic degradation containing anti-tumor activity. Journal of Applied Phycology, v. 15, p. 297-303, 2003.

HAROUN-BOUHEDJA, F.; ELLOUALI, M.; SINQUIN, C.; BOISSON-VIDAL, C. Relationship between Sulfate Groups and Biological Activities of Fucans. Thrombosis Research, v. 100, p. 453-459, 2000.

HEMMINGSON, J. A.; FALSHAW, R.; FURNEAUX, R. H.; THOMPSON, K. Structure and antiviral activity of the galactofucan sulfates extracted from Undaria pinnatifida (Phaeophyta). Journal of Applied Phycology, v. 18, p. 185-193, 2006.

HOLDT, S. L.; KRAAN, S. Bioactive compounds in seaweed: functional food applications and legislation. Journal of Applied Phycology, v. 23, p. 543-597, 2011.

JIAO, G.; YU, G.; ZHANG, J.; EWART, H. S. Chemical Structures and Bioactivities of Sulfated Polysaccharides from Marine Algae. Mar. Drugs, v. 9, p. 196-223, 2011.

KEARL M., KEARL T. (United States). Fucoidan delivery system. WO 2006130844 A2, 2 jun. 2006, 7 dez. 2006.

KILINÇ, B.; CIRIK, S.; TURAN, G.; TEKOGUL, H.; KORU, E. Seaweeds for Food and Industrial Applications, 2013. Disponível Em: http://cdn.intechopen.com/pdfs/41694/InTechSeaweeds_for_food_and_industrial_applicati ons.pdf. Acesso em: 27.04.14.

KIM, K. T.; RIOUX, L. E.; TURGEON, S. L. Alpha-amylase and alpha-glucosidase inhibition is differentially modulated by fucoidan obtained from Fucus vesiculosus and Ascophyllum nodosum. Phytochemistry, v. 98, p. 27-33, 2014.

KIM, K.J.; LEE, O.H.; LEE, H.H.; LEE, B.Y. A 4-week repeated oral dose toxicity study of fucoidan from the Sporophyll of Undaria pinnatifida in Sprague-Dawley rats. Toxicology, v. 267, p. 154-158, 2010.

KITAMURA, K.; MATSUO, M.; YASUI, T. Enzymic degradation of fucoidan by fucoidanase from the hepatopancreas of Patinopecten yessoensis. Biosci. Biotechnol. Biochem., v. 56, p. 490-494, 1992.

KLARZYNSKI, O.; DESCAMPS, V.; PLESSE, B.; YVIN, J.C.; KLOAREG, B.; FRITIG, B. Sulfated fucan oligosaccharides elicit defense responses in tobacco and local and systemic resistance against tobacco mosaic virus. Mol. Plant Microbe Interact, v. 16, p. 115-122, 2003.

KNUTSEN, S. H.; MURANO, E.; D'AMATO, M.; TOFFANIN, R.; RIZZO, R.; PAOLETTI, S. Modified procedures for extraction and analysis of carrageenan applied to the red alga Hypnea musciformis. Journal of Applied Phycology, v. 7, p. 565-576, 1995.

KUMAR, S.; GODIYA, C. B.; SIDDHANTA, A. K. Carrageenan from Sarconema scinaioides (Gigartinales, Rhodophyta) of Indian waters. Carbohydrate Polymers, v. 87, p. 1657- 1662, 2012.

KUSAYKIN, M.; BAKUNINA, I.; SOVA, V.; ERMAKOVA, S.; KUZNETSOVA, T.; BESEDNOVA, N.; ZAPOROZHETS, T.; ZVYAGINTSEVA, T. Structure, biological 
activity, and enzymatic transformation of fucoidans from the brown seaweeds. Biotechnol, v. 3, p. 904-915, 2008.

LI, B.; LU, F.; WEI, X.; ZHAO, R. Fucoidan: structure and bioactivity. Molecules, v. 13, p. 1671-1695, 2008.

LI, L.; NI, R.; SHAO, Y.; MAO, S. Carrageenan and its applications in drug delivery. Carbohydrate Polymers, v. 103, p. 1- 11, 2014.

LUO, D.; ZHAN, Q.; WANG, H.; CUI, Y.; SUN, Z.; YANG, J.; et al. Fucoidan protects against dopaminergic neuron death in vivo and in vitro. European Journal of Pharmacology, v. 617, p. 33-40, 2009.

MABEAL, S.; FLEURENCE, J. Seaweed in food products: biochemical and nutritional aspects. Trends in Food Science \& Technology, v. 4, p. 103-107, 1993.

MARCEL TRADING CORPORATION. (2006). Disponível em http://www.marcelcarrageenan.com. Acessado em: 30.04.2014.

MATHIESON, A. C.; TVETER, E. Carrageenan ecology of Gigartina stellata (stackhouse) batters. Aquatic Botany, v. 2, p. 353-361, 1976.

MATOU, S.; HELLEY, D.; CHABUT, D.; BROS, A.; FISCHER, A. M. Effect of fucoidan on fibroblast growth factor-2-induced angiogenesis in vitro. Thrombosis Research, v. 106, p. 213-221, 2002.

MATUlEWICZ, M. C.; CEREZO, A. S. The carrageenan from Iridaea undulosa B.; Analysis, fractionation and alkaline treatment. Journal of the Science of Food and Agriculture, v. 31, p. 203-213, 1980.

MCCANDLESS, E. L.; CRAIGIE, J. S.; HANSEN, J. E. Carrageenans of gametangial and tetrasporangial stages of Iridaea cordata (Gigartinaceae). Canadian Journal of Botany, v. 53, n. 20, p. 2315-2318, 1975.

McHUGH, D. J. Cap. 7 Carrageenan. In A guide to the seaweed industry: FAO fisheries technical paper. Rome: Food and Agriculture Organization of the United Nations, 2003. ISSN 0429-9345.

MOU, H.; XIAOLU, J.; HUASHI, G. A kappa-carrageenan derived oligosaccharide prepared by enzymatic degradation containing anti-tumor activity. J. Appl. Phycol, v. 15, p. 297-303, 2003.

MUTHUSWAMY, E.; RAMADEVI, S. S.; VASAN, H. N.; GARCIA, C.; NOE, L.; VERELST, M. Highly stable Ag nanoparticles in agar-agar matrix as inorganic-organic hybrid. Journal of Nanoparticle Research, v. 9, n. 4, p. 561-567, 2007.

PELLICO, M. A., inventor; Laclede Professional Products, Inc., assignee (United States). Agar gel topical dressing. US 4291025 A1, 11 abr. 1980, 22 set. 1981.

PERCIVAL, E.; McDOWELL, R. H. Chemistry and enzymology of marine algal polysaccharides. New York: Academic Press, p. 219, 1967.

PEREIRA, L. Population Studies and Carrageenan Properties in Eight Gigartinales (Rhodophyta) from Western Coast of Portugal. The ScientificWorld Journal, V. 2013, P. 1$11,2013$.

PERERA, J. G.; MESQUITA, J. X.; ARAGÃO, K. S.; FRANCO, A. X.; SOUZA, M. H. L. P.; BRITO, T. V.; DIAS, J. M.; SILVA, R. O.; MEDEIROS, J. V. R.; OLIVEIRA, J. S.; ABREU, C. M. W.S.; DE PAULA, R. C. M.; BARBOSA, A. L. R.; FREITAS, A. L. P. 
Polysaccharides isolated from Digenea simplex inhibit inflammatoryand nociceptive responses. Carbohydrate Polymers, v. 108, p. 17-25, 2014.

PÉREZ-RECALDE, M.; MATULEWICZ, M. C.; PUJOL, C. A.; CARLUCCI, M. J. In vitro and in vivo immunomodulatory activity of sulfatedpolysaccharides from red seaweed Nemalion helminthoides. International Journal of Biological Macromolecules, v. 63, p. 3842, 2014.

POMIN, V. H.; MOURAO, P. A. S. Structure, biology, evolution, and medical importance of sulfated fucans and galactans. Glycobiology, v. 18, p. 1016-1027, 2008.

PONCE, N. M. A.; P.UJOL, C. A.; DAMONTE, E. B.; FLORES, M. L.; STORTZ, C. A. Fucoidans from the brown seaweed Adenocystis utricularis: extraction methods, antiviral activity and structural studies. Carbohydrate Research, v. 338, p. 153-165, 2003.

PRADO, H. J.; CIANCIA, M.; MATULEWICZ, M. C. Agarans from the red seaweed Polysiphonia nigrescens (Rhodomelaceae, Ceramiales). Carbohydrate research, v. 343, n. 4, p. 711-718, 2008.

PRAJAPATI, V. D.; MAHERIYA, P. M.; JANI, G. K.; SOLANKI, H. K. Carrageenan: A natural seaweed polysaccharide and its applications. Carbohydrate polymers, v. 105, p. 97$112,2014$.

PUKYONG NATIONAL UNIVERSITY INDUSTRY-ACADEMIC COOPERATION FOUNDATION (Korea). Se-Kwon Kim, Young-Sook Cho. Pharmaceutical compositions containingfucoidan for stimulating and activating osteogenesis. US 20110301119 A1, 5 nov. 2009, 8 dez. 2011.

PULANNA SP. ZO.O (Poland). Miroslaw Skwarek, Michael Skwarek. Natural multiphase cosmetics. EP 2633848 A1, 6 ago. 2012, 4 set. 2013.

RINAUDO, M. Main properties and current applications of some polysaccharides as biomaterials. Polymer International, v. 57, p. 397-430, 2008.

RINAUDO, M. Non-Covalent Interactions in Polysaccharide Systems. Macromolecular Bioscience, v. 6, p. 590-610, 2006.

RINAUDO, M. Role of Substituents on the Properties of Some Polysaccharides, Biomacromolecules, v. 5, p. 1155-1165, 2004.

ROCHA, H. A. O.; FARIAS, E. H. C.; BEZERRA, L. C. L. M.; ALBUQUERQUE, I. R. L.; MEDEIROS, V. P.; QUEIROZ, K. C. S.; LEITE, E. L. Polissacarídeos sulfatados de algas marinhas com atividade anticoagulante. Infarma, v. 16, n. 1-2, p. 82-87, 2004.

RODRIGUES, J. A. G.; TORRES, V. M.; ALENCAR, D. B.; SAMPAIO, A. H.; FARIAS, W. R. L. Extração e atividade anticoagulante dos polissacarídeos sulfatados da alga marinha vermelha Halymenia pseudofloresia. Revista Ciência Agronômica, v. 40, n. 2, p. 224-231, 2009.

RODRÍGUEZ, M. C.; MATULEWICZ, M. C.; NOSEDA, M. D.; DUCATTI, D. R. B.; LEONARDI, P. I. Agar from Gracilaria gracilis (Gracilariales, Rhodophyta) of the Patagonic coast of Argentina-Content, structure and physical properties. Bioresource technology, v. 100, n. 3, p. 1435-1441, 2009.

ROSA, M. D. Biological properties of carrageenan. J. Pharm. Pharmac., v. 24, p. 89-102, 1972.

SANTOS, G. A. Carrageenans of Species of Eucheuma J. Agardh and Kappaphycus Doty (Solieriaceae, Rhodophyta). Aquatic Botany, v. 36, p. 55-67, 1989. 
Science Photo Library. Disponível em: https://www.sciencephoto.com/. Acesso em 27.04.14.

SEZER, A. D. (Turkey). Fucoidan multiparticulate drug carrier systems. WO 2006091180 A2, 25 fev. 2005, 31 ago. 2006.

SIDDHANTA, A. K.; GOSWAMI, A. M.; SHANMUGAM, M.; MODY, K. H.; RAMAVAT, B. K.; MAIRH, O.P. Sulphated galactans of marine red alga Laurencia spp.(Rhodomelaceae, Rhodophyta) from the west coast of India. Indian journal of marine sciences, v. 31, n. 4, p. 305-309, 2002.

SOUSA, A. P. A. DE; TORRES, M. R.; PESSOA, C.; MORAES, M. O. DE, ROCHA FILHO, F. D.; ALVES, A. P. N. N.; COSTA-LOTUFO, L. V. In vivo growth-inhibition of Sarcoma 180 tumor by alginates from brown seaweed Sargassum vulgare. Carbohydrate Polymers, v. 69, p. 7-13, 2007.

SPRINGER, G.F.; WURZEL, H.A.; MCNEAL, G.M., JR.; ANSELL, N.J.; DOUGHTY, M.F. Isolation of anticoagulant fractions from crude fucoidin. Proc. Soc. Exp. Biol. Med, v. 94, p. 404-409, 1957.

THOMES, P.; RAJENDRAN, M.; PASANBAN, B.; RENGASAMY, R. Cardioprotective activity of Cladosiphon okamuranus against isoproterenol induced myocardial infraction in rats. Phytomedicine, v. 18, p. 52-57, 2010.

TOYAMA, M.H.; TOYAMA, D.O.; TORRES, V.M.; PONTES, G.C.; FARIAS, W.R.L.; MELO, F.R.; OLIVEIRA, S.C.B.; FAGUNDES, F.H.R.; DIZ FILHO, E.B.S.; CAVADA, B.S. Effects of Low Molecular Weight Sulfated Galactan Fragments From Botryocladia occidentalis on the Pharmacological and Enzymatic Activity of Spla2 From Crotalus Durissus Cascavella. Protein J., p. 1-5, 2010.

TRC. Toronto Research Chemicals. L-fucose. Disponível em: http://www.trccanada.com/search_cat.php?Search=L-fucose\&qsearch=Quick+Search. Acesso em 27.04.14.

UNIV CAPITAL MEDICAL SCIENCES (China). Luo Dali, Yang Wenzhe, Cui Wentong, Zhang Quanbin. Novel medicinal application of fucoidan polysaccharide sulfate. CN 103239472 A, 10 maio 2013, 14 ago. 2013b.

UNIV CAPITAL MEDICAL SCIENCES (China). Luo Dali, Yu Xinfeng, Zhang Chao, Cui Wentong, Zhang Quanbin. Application of fucoidan polysaccharide sulfate in preparing drug for preventing and/or treating diabetic cardiomyopathy. $\mathrm{CN}$ 103230411, 20 maio 2013, 7 ago. 2013a.

UNIVERSIDADE FEDERAL DE PERNAMBUCO (Brasil). Ricardo Yara, Cláudia Sampaio de Andrade Lima, Beate Saegesser Sos Santos, Júlio César Bezerra Pereira. Water-soluble agar polymer film and method for the production thereof. WO 2013113086 A1, 8 fev. 2013, 8 ago. 2013.

USOV, A. I. Polysaccharides of the red algae. Advances in carbohydrate chemistry and biochemistry, v. 65, p. 116, 2011.

USOV, A. I.; ELASHVILI, M. Y. Polysaccharides of algae. Investigation of sulfated galactan from Laurencia nipponica Yamada (Rhodophyta, Rhodomelaceae) using partial reductive hydrolysis. Botanica marina, v. 34, n. 6, p. 553-560, 1991.

VERKLEIJ, F. N. Seaweed extracts in agriculture and horticulture: a review. Biological Agriculture \& Horticulture, v. 8, n. 4, p. 309-324, 1992. 
VIDOTTI, E. C.; ROLLEMBERG, M. C. E. Algas: da economia nos ambientes aquáticos à bioremediação e à química analítica. Quim. Nova, v. 27, n. 1, p. 139-145, 2004.

VILLANUEVA, R. D.; ROMERO, J.B.; RAGASA, A. L. R.; MONTAÑO, M. N. E. Agar from the red seaweed, Laurencia flexilis (Ceramiales, Rhodophyta) from northern Philippines. Phycological Research, v. 58, p. 151-156, 2010a.

VILlANUEVA, R. D.; SOUSA, A. M. M.; GONÇALVES, M. P.; NILSSON, M.; HILLIOU, L. Production and properties of agar from the invasive marine alga, Gracilaria vermiculophylla (Gracilariales, Rhodophyta). J Appl Phycol, v. 22, p. 211-220, 2010b.

WALTER AMES RULLMAN (United States). Cereal preparation. US 1163175, 12 maio 1915, 7 dez. 1915.

WEBBER, V.; CARVAlHO, S. M.; BARRETO, P. L. M. Molecular and rheological characterization of carrageenan solutions extracted from Kappaphycus alvarezii. Carbohydrate Polymers, v. 90, p. 1744- 1749, 2012.

WHYTE, J. N., ENGLAR, J. R. The agar component of the red seaweed Gelidium purpurascens. Phytochemistry, v. 20, n. 2, p. 237-240, 1981.

WIJESEKARA, I.; PANGESTUTI, R.; KIM, S. K. Biological activities and potential health benefits of sulfated polysaccharides derived from marine algae. Carbohydrate Polymers, v. 84, p. 14-21, 2011.

WONG, K. F.; CRAIGIE, J. S. Sulfohydrolase Activity and Carrageenan Biosynthesis in Chondrus crispus (Rhodophyceae) Plant Physiol. V. 61, P. 663-666, 1978.

YANG, B.; YU, G.; ZHAO, X.; REN, W.; JIAO, G.; FANG, L.; WANG, Y.; DU, G.; TILLER, C.; GIROUARD, G.; BARROW, C.J.; EWART, H.S.; ZHANG, J. Structural characterisation and bioactivities of hybrid carrageenan-like sulphated galactan from red alga Furcellaria lumbricalis. Food Chem, v. 124, p. 50-57, 2011.

YU, Q.; YAN, J.; WANG, S.; JI, L.; DING, K.; VELlA, C.; WANG, Z..; HU, Z. Antiangiogenic effects of GFP08, an agaran-type polysaccharide isolated from Grateloupia filicina. Glycobiology, v. 22, n. 10, p. 1343-1352, 2012.

ZHANG, H. J.; MAO, W. J.; FANG, F.; LI, H. Y.; SUN, H. H.; CHEN, Y.; QI, X. H. Chemical characteristics and anticoagulante activities of a sulfated polysaccharide and its fragments from Monostroma latissimum. Carbohydrate Polymers, v. 71, n. 03, p. 428-434, 2008.

ZHOU, G.; SUN, Y.; XIN, H.; ZHANG, Y.; LI, Z.; XU, Z. In vivo antitumor and immunomodulation activities of different molecular weight lambda-carrageenans from Chondrus ocellatus. Pharmacological Research, v. 50, p. 47-53, 2004. 